\title{
PERFIL E DESTINO OCUPACIONAL DE EGRESSOS GRADUADOS EM CIÊNCIAS BIOLÓGICAS NAS MODALIDADES A DISTÂNCIA E PRESENCIAL
}

\author{
Dirceu Esdras Teixeira* \\ Luiz Carlos dos Santos Ribeiro** \\ Keila Mara Cassiano*** \\ Masako Oya Masuda**** \\ Marlene Benchimol ${ }^{* * * *}$
}

RESUMO: O presente trabalho tem como objetivo evidenciar o perfil dos egressos de alguns cursos de graduação em Ciências Biológicas no Estado do Rio de Janeiro. O instrumento de pesquisa utilizado foi um questionário online, composto por perguntas multiopcionais. Este foi respondido por 241 egressos, sendo 83 do ensino a distância e 158 do ensino presencial, de universidades públicas e uma privada. Os resultados mostraram a predominância de mulheres, de cor branca e idade média de 23 anos, na conclusão do curso dos egressos do ensino presencial, e 33 no ensino a distância. Além disso, percebeu-se o predomínio do cargo de professor, principalmente no Ensino Fundamental II e no Ensino Médio e renda mensal de 3 a 4 salários mínimos.

Palavras-chave: Destino ocupacional. Mercado de trabalho. Ciências Biológicas.

\section{PROFILE AND PROFESSIONAL DESTINATION OF GRADUATED STUDENTS IN BIOLOGICAL SCIENCES BOTH IN TRADITIONAL AND DISTANCE EDUCATION MODALITIES}

ABSTRACT: This paper aims to highlight the profile of the graduates of some degree courses in Biological Sciences in the State of Rio de Janeiro, Brazil. The survey instrument used was an online questionnaire consisting of multiple choice questions. This was answered by 241 graduate students, being 83 of distance learning and 158 of classroom teaching, from public and one private universities. The results showed the predominance of women, white, an average age of 23 years, at the course completion coming from traditional classroom, and 33 from distance learning. Moreover, it was noticed the predominance of professorship, especially in Secondary School and High School and monthly income of 3-4 minimum wages.

Keywords: Occupational Destinations. Labor market. Biological Sciences. 


\section{INTRODUÇÃO}

Os cursos de graduação no Brasil apresentaram um notável crescimento nos últimos anos, tanto para a modalidade presencial quanto a distância. O último Censo da Educação Superior, referente ao ano de 2009, realizado pelo Instituto Nacional de Estudos e Pesquisas Educacionais Anísio Teixeira (INEP) mostrou que os cursos de graduação apresentaram um acréscimo de $13 \%$ em relação ao ano de 2008. Dados do Ministério da Educação (MEC) indicam um crescimento significativo nos cursos de educação a distância (EaD) desde o ano de 2001, quando foram contabilizados pouco mais de 5 mil estudantes, chegando a 814 mil alunos em 2009. Comparando as modalidades de ensino, os cursos de EaD evidenciaram um aumento de 30,4\%, enquanto os presenciais, de 12,5\%, em relação ao ano de 2008 (INEP, 2010). Esse mesmo estudo mostrou que o curso de Ciências Biológicas, objeto do nosso estudo, ocupa a décima colocação no ranking dos dez maiores cursos de graduação (presencial e a distância reunidos), além do décimo lugar na modalidade presencial e o sétimo na modalidade a distância. Diante disso, é necessário conhecer o perfil do biólogo que vem sendo formado no estado do Rio de Janeiro e, assim, avaliar como o ensino superior prepara para a inserção desse profissional no mercado de trabalho.

A opinião do egresso é uma importante ferramenta de acompanhamento da trajetória profissional do aluno, das competências adquiridas durante a graduação, além da atuação no mercado de trabalho.

Pesquisas com egressos são realizadas desde a década de 1930, nos Estados Unidos, com estudos relacionados à opinião sobre satisfação no trabalho, relação entre as universidades e o mercado de trabalho e sua posterior transição. Somente na década de 1980 os estudos expandiram seu foco para investigar as competências adquiridas durante a faculdade (CABRERA, WEERTZ e ZULICK, 2005). Delaney (2000) argumenta que o trabalho com pesquisa envolvendo os egressos pode favorecer uma melhoria do ensino superior, uma vez que informações sobre as competências adquiridas durante a graduação promoveriam mudanças que assegurariam aos formandos um preparo melhor para a atuação no mercado de trabalho. Entretanto, há poucas informações sobre os egressos dos cursos de Ciências Biológicas, e os poucos estudos existentes são relacionados a relatórios institucionais.

A profissão do biólogo foi reconhecida no Brasil em 03 de setembro de 1979 pela Lei no .6684 e pelo Decreto nº 88.438 de 28 de junho de 1983. Fiscalizada e orientada a respeito do exercício profissional e ético pelas autarquias federais denominadas Conselho Federal de Biologia - CFBio e Conselhos Regionais de Biologia, a atividade especializada do graduado em Ciências Biológicas é tipicamente absorvida pelo mercado da educação, do Ensino Fundamental até o Ensino Superior.

Entretanto, o Biólogo é também indispensável em atividades de assessoria, consultoria, supervisão técnica, planejamento, coordenação e pesquisas técnicocientíficas em órgãos governamentais, empresas privadas e institutos de pesquisas 
que têm alguma relação com seres vivos ou com o meio ambiente, ou que precisam compreender os processos e mecanismos que regulam ou influenciam a vida vegetal e animal.

Atualmente, o biólogo apresenta relevância na sociedade em que vivemos graças às inúmeras possibilidades da profissão, que vão desde a preservação do meio ambiente até a pesquisa básica e aplicada. Uma vez que essas abordagens são de interesse social, econômico e político em todo o mundo, os conhecimentos desses profissionais se tornam importantes, permitindo a inserção direta ou indireta do biólogo em vários campos da atividade econômica e do conhecimento. Espera-se, então, que a população de graduados em Ciências Biológicas tenha uma ampla inserção no mercado de trabalho, principalmente nos grandes centros econômicos, fornecendo suporte de conhecimento adquirido na universidade para distintos ramos. O presente trabalho tem como objetivo traçar um perfil do egresso de cursos de graduação em Ciências Biológicas no estado do Rio de Janeiro, avaliando sua transição, destino ocupacional e renda. Deseja-se investigar se a inserção do biólogo no estado corrobora com a esperada permeabilidade nos diversos ramos de atividades que compete a esse profissional e estimar parâmetros quantitativos da renda mensal percebida, avaliando o efeito positivo da graduação na situação ocupacional desses egressos.

\section{METODOLOGIA}

A pesquisa foi feita com base em amostras de egressos que concluíram o curso de Ciências Biológicas, presenciais e a distância, entre os anos de 2005 e 2009 no estado do Rio de Janeiro. As seguintes universidades foram pesquisadas: (1) instituições públicas: Universidade do Estado do Rio de Janeiro (UERJ), Universidade Estadual do Norte Fluminense Darcy Ribeiro (UENF) e Universidade Federal do Rio de Janeiro (UFRJ) - vale a pena ressaltar que essas mesmas universidades oferecem ensino a distância $(\mathrm{EaD})$ através o Consórcio CEDERJ (Centro de Educação Superior a Distância do Estado do Rio de Janeiro); e (2) em relação à instituição privada, os egressos oriundos da Universidade Santa Úrsula (USU).

Dada a diversidade da amostra no que diz respeito ao tipo de instituição (pública/privada) e à modalidade de ensino (presencial e a distância), a análise foi feita distinguindo tais características sempre, no intuito de investigar se havia diferenças específicas e significativas de perfil e atividade profissional dos egressos oriundos dos distintos tipos de instituições.

$\mathrm{O}$ instrumento de coleta de dados desta pesquisa foi um questionário disponibilizado online na internet através do site www.enquetefacil.com apresentando questões multiopcionais. O contato com os egressos ocorreu através de listas de e-mails do ambiente virtual de aprendizagem (no caso dos egressos de EaD) e de professores e alunos, ou por meio de comunidades, em redes sociais, no caso de alunos dos cursos presenciais. Foi primeiramente informado aos egressos o 
compromisso de sigilo de todos os dados pessoais, oferecendo-se também a opção de total anonimato. Em seguida, foi enviada uma correspondência eletrônica (e-mail) com o link do questionário para 681 graduados. Obtivemos resposta positiva de participação de 241 egressos.

Essa técnica de coleta de dados apresenta algumas vantagens, já citadas por Rossi e Slongo (1998, p. 117):

[...] quando os elementos da amostra se encontram dispersos geograficamente a coleta via questionário pelo correio pode ser recomendável, uma vez que o custo unitário de cada entrevista pessoal tende a ser, nesses casos, muito elevado. Outra situação que pode representar vantagem da coleta pelo correio em relação à entrevista pessoal, é quando o número de elementos da amostra é muito alto. Nestes casos o controle da equipe de entrevistadores, necessários para a realização dos trabalhos de campo, pode tornar-se muito complexo e vulnerável.

O teste de Kruskall-Wallis foi utilizado para análise das diferenças entre grupos. Uma vez verificada a não normalidade da distribuição das variáveis quantitativas, utilizou-se, em seguida, o teste de Kolmogorov-Smirnov. Diferenças entre grupos em relação a variáveis qualitativas foram investigadas pelo teste Qui-Quadrado. Para aquelas evoluções antes e depois da graduação, foi utilizado o teste de Mcnemar-Bowker. Diferenças foram consideradas significativas sempre que os p-valores associados aos testes se apresentassem menores que 5\%.

No questionário, o egresso foi indagado sobre a atividade profissional antes e depois do curso. Com esses dados, propusemos fazer um estudo evolutivo de tabela cruzada, com o intuito de analisar a mobilidade desse respondente, considerando a atividade profissional atual após a graduação em relação à atividade que ele tinha antes do curso. Quando o respondente não alterou o status, considerou-se que ele não apresentou mobilidade de atividade profissional. Se o respondente não exercia atividade profissional antes do curso e após o curso passou a ter, então considerou-se que ele teve uma mobilidade positiva. Também foi considerada mobilidade positiva o caso em que o respondente, antes, tinha atividade profissional fora da área e depois do curso passou a trabalhar na área de formação. Para os demais casos, ou seja, quando o respondente tinha atividade profissional antes da graduação e depois não a teve mais, ou se o respondente trabalhava na área e depois do curso passou a trabalhar fora da área, foi considerado que o respondente teve mobilidade negativa.

O conceito de mobilidade de atividade profissional foi estendido para a definição de mobilidade de classe de renda. Se o respondente não alterou a classe de renda percebida, antes e depois da graduação, foi considerado que ele não teve mobilidade. Se ele passou a ganhar menos depois da graduação, considerou-se que ele teve mobilidade negativa, e se passou para classe de renda superior, a mobilidade de renda foi considerada positiva. 


\section{CARACTERIZAC̣ÃO DA AMOSTRA}

A amostra objeto deste estudo foi formada por 241 egressos, sendo 83 da modalidade de EaD (graduados na UENF, UERJ e UFRJ através do consórcio CEDERJ) e 158 da modalidade de ensino presencial: 46 egressos da UENF, 35 da UERJ, 33 da UFRJ e 44 egressos da USU. A distribuição de frequência percentual pode ser vista na Figura 1. Sendo assim, a característica predominante da amostra de egressos foi a natureza pública da instituição de ensino que os diplomou; somente $18,3 \%$ da amostra foi oriunda da rede privada. Também predominaram, na amostra, profissionais formados na modalidade presencial, totalizando $65,6 \%$, contra 34,4\% de profissionais diplomados por EaD.

Figura 1: Distribuição das instituições em que se formaram os egressos envolvidos na pesquisa.

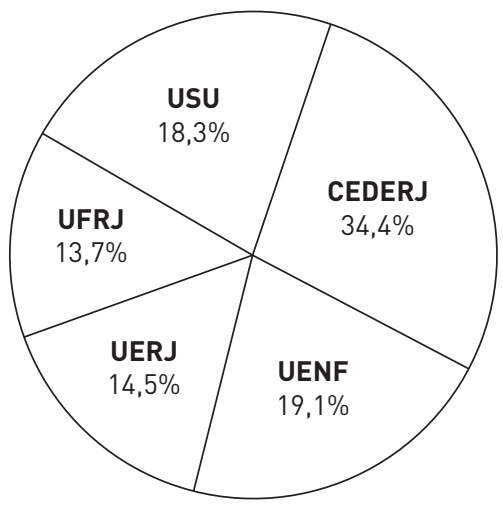

Os resultados do presente trabalho mostraram um predomínio de mulheres no grupo de egressos do Curso de Ciências Biológicas. Nessa amostra, elas representaram $73 \%$ dos respondentes e os homens $27 \%$. Não houve diferenças significativas entre as proporções de homens e mulheres nas cinco instituições (p-valor=0,372 do teste Qui-Quadrado).

Além disso, 61,4\% dos egressos declararam ser da cor branca, segundo classificação do IBGE. Outros 24,9\% respondentes se consideraram "pardos". Nos grupos de todas as instituições, os brancos representaram mais de 50\%, chegando a ser 75\% da amostra da USU. Os pretos, amarelos e indígenas foram minorias, com percentuais somando $13,7 \%$ da amostra.

A faixa etária média de conclusão do curso foi de 26 anos, variando entre 20 a 57 anos. A média de idade dos egressos de cursos presenciais foi próxima, entre 21 e 24 anos (Tabela 1). Os alunos de EaD se formaram com idade média superior, igual a 33 anos. Em todos os grupos de ensino presencial foi verificada baixa variabilidade na idade ao se formar, mas algumas idades foram discrepantes das demais, como podem ser verificadas nos pontos marcados pelos símbolos ${ }^{\circ} \mathrm{e}^{*}$ nos Box-plots exibidos na Figura 2. Tais símbolos representam outliers na distribuição de idade. 
As diferenças observadas na idade ao se formar dos cinco grupos, foram estatisticamente significativas ( $\mathrm{p}$-valor=0.000), resultante do teste de Kruskall Wallis. Em análise post hoc concluiu-se que não há diferenças significativas na idade ao se formar entre os profissionais dos cursos presenciais da UENF, UERJ e UFRJ. Contudo, a idade de conclusão do curso dos alunos dessas instituições foi significativamente distinta daquela dos graduados pelo CEDERJ (EaD) e dos formados pela USU, que apresentaram respectivamente, maiores e menores estatísticas de idade ao formar.

Tabela 1: Principais estatísticas da distribuição da idade dos respondentes ao se formarem.

P25 = Percentil 25, P75 = Percentil 75 D.P. $=$ Desvio Padrão; C.V. $=$ Coeficiente de Variação.

\begin{tabular}{|c|c|c|c|c|c|c|c|c|c|}
\hline Instituição & Média & Mediana & Moda & Mínimo & Máximo & P25 & P75 & D.P & C.V \\
\hline CEDERJ & 32,7 & 31.5 & 26 & 20 & 57 & 24 & 41 & 9,64 & 0,29 \\
\hline UENF & 23,1 & 22 & 21 & 20 & 41 & 21 & 24 & 3,69 & 0,16 \\
\hline UERJ & 22,4 & 22 & 21 & 20 & 29 & 21 & 23.3 & 1,97 & 0,09 \\
\hline UFRJ & 22,5 & 22 & 22 & 20 & 29 & 21 & 24 & 2,11 & 0,09 \\
\hline USU & 21,5 & 21 & 21 & 20 & 26 & 21 & 22 & 1,25 & 0,06 \\
\hline Geral & 25,9 & 23 & 21 & 20 & 57 & 21 & 26 & 7,76 & 0,30 \\
\hline
\end{tabular}

Figura 2 - Box plot da idade dos respondentes no momento da conclusão do curso.

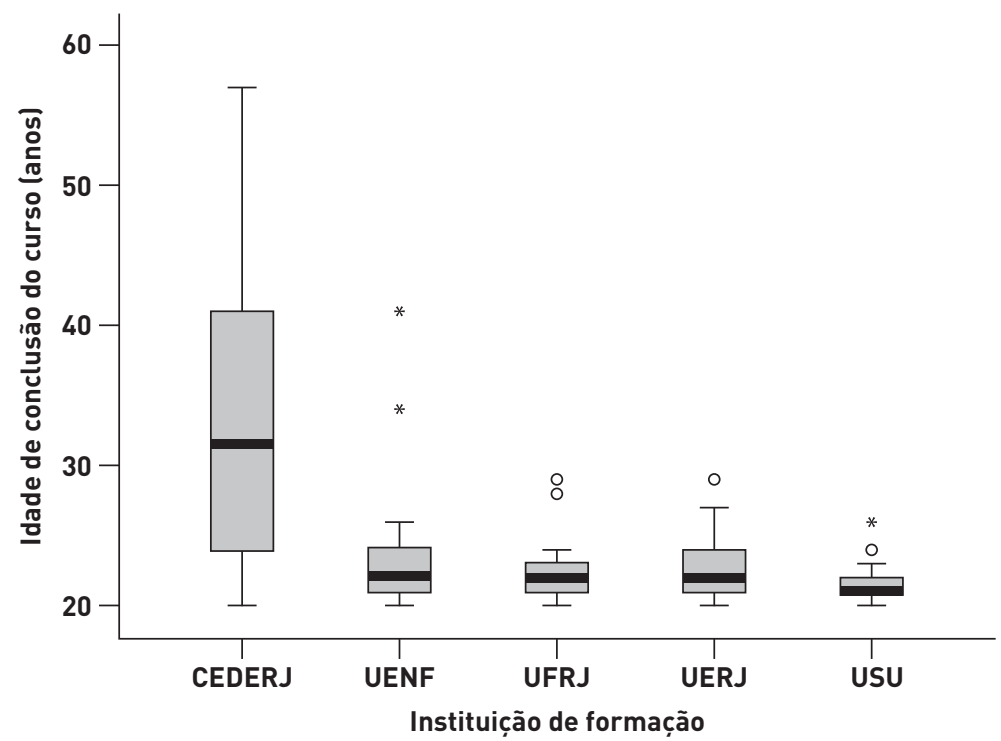


A habilitação predominante dos egressos foi a licenciatura com 65,1\% (ou 85,5\% considerando também aqueles que têm dupla habilitação). A amostra apresentou uma participação total de 75 bacharéis, correspondendo a 31,1\% dos participantes da pesquisa. Conforme apresentado na Tabela 2 , a maioria dos profissionais da instituição privada (USU) possuíam as duas habilitações, licenciatura e bacharelado, com proporção de $84,1 \%$. Outros 4,7\% deles possuíam apenas o bacharelado, e a minoria dos formados na instituição privada possuíam apenas a licenciatura, diferente do que ocorreu com os alunos das instituições públicas onde a maioria tem apenas a licenciatura. A proporção de bacharéis foi maior na UFRJ $(45,4 \%)$ e UENF (34,8\%), enquanto na UERJ foi menor, igual a 14,3\%.

Tabela 2 : Habilitação do curso de formação do respondente.

\begin{tabular}{|c|c|c|c|c|c|c|c|}
\hline Habilitação & EaD & UENF & UERJ & UFRJ & USU & Geral & $\%$ \\
\hline Licenciatura & 82 & 27 & 30 & 17 & 1 & 157 & 65 \\
\hline Bacharelado & 0 & 14 & 3 & 7 & 2 & 26 & 11 \\
\hline Ambos & 0 & 2 & 2 & 8 & 37 & 49 & 20 \\
\hline Não respondeu & 1 & 3 & 0 & 1 & 4 & 9 & 4 \\
\hline Total & 83 & 46 & 35 & 33 & 44 & 241 & 100 \\
\hline
\end{tabular}

Os egressos gastaram de 7 a 15 semestres para se formarem, sendo que $82,4 \%$ levaram de 8 a 10 semestres e o tempo médio global para a conclusão do curso no grupo pesquisado foi de 9,3 semestres (Tabela 3). As menores estatísticas ocorreram para os graduados do curso presencial da USU (instituição privada) que se formaram, em média, em 8,6 semestres. Para a EaD, o percentual de alunos que terminaram o curso em 7 ou 8 semestres foi de apenas 23,2\%. Para o grupo de alunos formados na UERJ, esse percentual foi de $41,3 \%$, e na UFRJ somente $24,2 \%$ dos alunos declararam se formar em até 8 semestres. A média do tempo gasto para se formar no curso EaD foi de 9,7 semestres (Tabela 3), superior aos demais, mas a mediana foi igual a dos alunos dos cursos presenciais da UERJ e UFRJ. Concluiu-se, pelo teste de Kruskall-Wallis, que não havia diferenças significativas no tempo que os alunos dos cursos presenciais da UENF, UERJ e UFRJ levaram para se formar, que foi predominantemente de 8 a 10 semestres. Os profissionais formados no curso EaD dessas mesmas instituições levaram um tempo significativamente maior do que seus colegas dos cursos presenciais. Já os formados pela USU levaram um tempo significativamente menor do que os alunos dos cursos presenciais das três instituições públicas. A variabilidade no tempo para a conclusão do curso foi também menor no grupo de alunos da USU. 
Tabela 3 - Principais estatísticas do tempo gasto em semestres para conclusão do curso. D.P. = Desvio Padrão; C.V. $=$ Coeficiente de Variação.

\begin{tabular}{|c|c|c|c|c|c|c|c|}
\hline Instituição & Média & Mediana & Moda & Mínimo & Máximo & D.P. & C.V \\
\hline CEDERJ & 9,7 & 9 & 9 & 7 & 15 & 1,54 & 0,16 \\
\hline UENF & 9,0 & 8 & 8 & 7 & 14 & 1,49 & 0,17 \\
\hline UERJ & 9,1 & 9 & 8 & 8 & 14 & 1,31 & 0,14 \\
\hline UFRJ & 9,6 & 9 & 9 & 7 & 14 & 1,62 & 0,17 \\
\hline USU & 8,6 & 8 & 8 & 7 & 11 & 0,89 & 0,10 \\
\hline Geral & 9,3 & 9 & 8 & 7 & 15 & 1,46 & 0,16 \\
\hline
\end{tabular}

Para a maioria dos respondentes (92,9\%), o curso de Ciências Biológicas foi o primeiro curso superior. Somente $6,6 \%(\mathrm{~N}=16)$ da amostra já possuíam outro curso superior e a maioria destes $(5,4 \%)$ eram egressos da EaD. Nos cursos presenciais, o número de profissionais que já possuíam outra graduação foi mais raro, havendo ocorrências de apenas dois casos na UENF e um na UERJ.

Verificamos que durante a graduação a maior parte dos egressos realizou estágios de iniciação científica, fato observado para $64,2 \%$ da amostra. A proporção de graduados que fizeram iniciação científica no grupo EaD foi bem menor $(18,3 \%)$ quando comparado com graduados dos cursos presenciais da UERJ (91,4\%), da USU (90,9\%), da UFRJ (87,9\%) e da UENF (82,6\%). O teste Qui-quadrado indicou que as diferenças nessas proporções foram estatisticamente significativas ( $\mathrm{p}$-valor $=0.000)$.

A maioria dos egressos das instituições de ensino envolvidas $(85,1 \%)$ declarou não ter feito outro curso de graduação, enquanto quase $5 \%$ dos egressos fizeram ou estavam fazendo outro curso na área no momento desta pesquisa, e 6,2\% fizeram cursos em área distinta de Ciências Biológicas. A maior porcentagem foi dos egressos da EaD que fazem outro curso de graduação (20,5\%). Na UENF, o percentual de egressos que fazem outro curso foi de 8,7\%; na UERJ, 8,6\%; na UFRJ, 18,2\%; e na USU, 9,1\%.

Como era de se esperar, os respondentes dos cursos presenciais fizeram pós-graduações na mesma área de formação (57,7\%). Em relação à pós-graduação houve menor procura dos alunos da EaD, apenas um percentual de 44,6\%, sendo, portanto, menor que os demais grupos aqui analisados. Os egressos das instituições públicas de ensino presencial fizeram pós-graduação com bons índices, sendo que UENF, UERJ e UFRJ destacaram-se com maiores percentuais de 87,0\%, $82,8 \%$ e $84,8 \%$, respectivamente. Na USU, 70,4\% dos egressos fizeram ou estão fazendo pós-graduação. 


\section{ATIVIDADE PROFISSIONAL}

Antes do curso de graduação, apenas 6,8\% dos alunos da instituição privada (USU) trabalhavam, enquanto que 74,4\% dos alunos do CEDERJ tinham atividade profissional. De modo similar, em pesquisa realizada, Vasconcelos e Lima (2010) observaram que 72,3\% dos licenciados de curso presencial trabalhavam durante a graduação de Ciências Biológicas da Universidade Federal de Pernambuco (UFPE). Os cursos presenciais públicos da nossa pesquisa mostraram que apenas 18,7\% dos estudantes trabalhavam durante o curso.

Depois de formados, o menor percentual de pessoas sem atividade profissional continuou sendo do grupo de egressos do CEDERJ (EaD), 14,6\%. Nos demais grupos, o percentual de formados sem atividade profissional chegou a ser mais que o dobro dessa proporção, sendo o maior valor entre os que se formaram na USU (40,9\%). Os percentuais de egressos em Biologia sem atividade profissional no Rio de Janeiro, estimados neste trabalho, foram altos quando comparados ao estudo de Freitas (2007) feito com 50 alunos egressos do curso de Ciências Biológicas da UNESC (2002-2005) em Criciúma, onde os autores verificaram que somente 4\% da amostra estavam sem atividade profissional após o curso. Porém, nesse mesmo estudo, os autores constataram que grande parte dos egressos não estava atuando na área da Biologia, possivelmente pela falta de oferta de trabalho na região.

No presente estudo, o percentual de pessoas que trabalhava fora da área diminuiu depois de concluída a graduação em quase todos os grupos de egressos. A exceção foi do grupo de egressos da USU, que antes do curso apresentava 2,3\% trabalhando fora da área, e depois do curso esse percentual passou a ser de 13,6\%. Entretanto, é importante destacar que poucos alunos (7,9\%) dessa instituição trabalhavam antes de entrarem na universidade. Após a graduação, o percentual geral de profissionais atuando fora da área foi de 17,5\%. No estudo de Freitas (2007), os autores encontraram estimativa bem maior, sendo $60 \%$ dos egressos de Ciências Biológicas formados pela UNESC trabalhando fora da área.

Quando indagados sobre os motivos que os levaram a atuarem fora da área de formação, a resposta mais frequente dentre os egressos do CEDERJ e da UFRJ foram "motivos pessoais". Os egressos da UERJ, UENF e da USU citaram o "mercado de trabalho saturado" para o formado em Ciências Biológicas. Além disso, os egressos da UENF e USU também citaram o fato de "ter encontrado melhor oportunidade fora da área".

Somente alguns profissionais do CEDERJ (14,6\%) e da USU (4,5\%) já trabalhavam na área antes da graduação. Após a graduação, os maiores percentuais de trabalhadores na área foram os formados pela UERJ, UFRJ e CEDERJ. O maior percentual de mobilidade positiva ocorreu no grupo de ex-alunos da UFRJ (72,7\%), que também apresentou a menor mobilidade negativa $(3,0 \%)$. A maior mobilidade negativa ocorreu para os alunos formados na UENF $(6,5 \%)$ e o maior percentual de ausência de mobilidade foi entre os alunos do CEDERJ (50,0\%). 
Dentre os cargos desempenhados, os resultados mostraram que a maioria dos egressos está trabalhando na docência (32,4\%). Observou-se que os ex-alunos estavam trabalhando em uma pequena variedade de cargos na área: 6,6\% trabalham com auditoria/consultoria especializada, 2,9\% trabalhavam como biólogos, 2,1\% executavam trabalhos técnicos em laboratório e $0,4 \%$ faziam outra atividade na área.

Quando questionados sobre a natureza da instituição, 49,0\% responderam onde exerceram sua atividade profissional. Dentre os que responderam, $72,0 \%$ declararam que trabalhavam em instituições públicas, com destaque para os egressos da UFRJ: 92,3\% trabalhavam em instituições públicas. Os resultados mostraram também que a proporção de egressos que trabalhava na rede privada foi maior no grupo de profissionais formados pela USU $(75,0 \%)$. As diferenças entre tais proporções das diversas instituições foram estatisticamente significativas ( $\mathrm{p}$-valor $=0.000$ do teste Qui-quadrado).

Dentre aqueles que declararam vínculo com a empresa onde exerciam atividade profissional, 33,6\% eram concursados, seguidos dos que trabalhavam com carteira assinada (14,9\%). Dos 81 concursados, nenhum era oriundo de instituição privada (USU). Desta instituição, a maioria que respondeu o tipo de vínculo declarou que trabalhava com carteira assinada. As maiores proporções de profissionais concursados foram de egressos da EaD e da UFRJ, 49,4\% e 48,5\% respectivamente. Dos profissionais formados pela UERJ a proporção de concursados foi de $34,3 \%$, e pela UENF foi de $26,1 \%$.

Entre os egressos que seguiram a carreira como professores, observamos predomínio de empregabilidade no Ensino Fundamental II e no Ensino Médio. O percentual de ex-alunos docentes de Ensino Superior foi de apenas 2,9\%. Os grupos da UERJ e do CEDERJ destacaram-se por apresentarem o maior percentual $(22,9 \%$ e 20,5\%, respectivamente) de egressos docentes no Ensino Médio, em pré-vestibular ou no Ensino Superior. No grupo oriundo da UENF, esse percentual foi de 10,9\%, enquanto na UFRJ foi de apenas 3,3\% e na USU foi de 6,8\% (Tabela 4).

Tabela 4: Nível de ensino em que os egressos docentes lecionam.

\begin{tabular}{|c|c|c|c|c|c|c|c|}
\hline & EaD & UENF & UERJ & UFRJ & USU & Total & $\%$ \\
\hline Fundamental I & 3 & 0 & 0 & 0 & 2 & 5 & 2,1 \\
\hline Fundamental II & 13 & 4 & 10 & 9 & 2 & 38 & 15,8 \\
\hline Médio & 13 & 3 & 6 & 1 & 1 & 24 & 10,0 \\
\hline Superior & 3 & 2 & 1 & 0 & 1 & 7 & 2,9 \\
\hline Pré-vestibular & 1 & 0 & 1 & 0 & 1 & 3 & 1,2 \\
\hline Não respondeu & 50 & 37 & 17 & 23 & 37 & 164 & 68,0 \\
\hline Total & 83 & 46 & 35 & 33 & 44 & 241 & 100,0 \\
\hline
\end{tabular}


Em relação ao número de empregos, 39,0\% dos respondentes tem um único emprego e a média geral foi de 1,5 atividades remuneradas por respondente. A menor média de número de atividades desempenhada foi dos profissionais formados pela UENF, de 1,3 atividades por egresso, e a maior média foi dos formados pela UFRJ, com 1,6.

A segunda atividade típica também é a docência, assinalada por $12.45 \%$ da amostra. Dentre os formados pela USU, a segunda atividade típica está relacionada a atividades diversas fora da área de formação.

\section{APROVAC̣ÃO EM CONCURSOS}

No grupo aqui estudado, o índice de aprovação geral em concursos foi de $80,7 \%$, sendo que 12 egressos não prestaram concursos durante ou após a graduação. Os ex-alunos presenciais da UERJ e UFRJ obtiveram 100\% de aprovações, seguidos pela $\mathrm{EaD}$, com 88,5\% de aprovação. Na USU, esse índice foi bem menor, de apenas 37,5\% (Tabela 5).

Tabela 5: Sobre a prestação de concursos públicos.

\begin{tabular}{|c|c|c|c|c|c|c|}
\hline Prestou concurso após a graduação? & EaD & UENF & UERJ & UFRJ & USU & Total \\
\hline Não & 8 & 1 & 0 & 1 & 2 & 12 \\
$\%$ & 13,3 & 9,1 & 0,0 & 14,3 & 20,0 & 12,6 \\
\hline Sim e fui aprovado & 46 & 5 & 7 & 6 & 3 & 67 \\
$\%$ & 76,7 & 45,5 & 100,0 & 85,7 & 30,0 & 70,5 \\
\hline Sim e fui reprovado & 6 & 5 & 0 & 0 & 5 & 16 \\
$\%$ & 10,0 & 45,5 & 0,0 & 0,0 & 50,0 & 16,8 \\
\hline Índice de aprovação em concurso (\%) & 88,5 & 50,0 & 100,0 & 100,0 & 37,5 & 80,7 \\
\hline
\end{tabular}

\section{REMUNERAC̣ÃO}

A renda mensal dos egressos antes e depois da graduação revelou que houve uma mobilidade positiva de classe de renda para 65,3\% (N=156) dos respondentes, ou seja, tais pessoas ganharam mais após cursarem a graduação (Tabela 6). Verificou-se também que não houve mobilidade de classe de renda para 30,3\% $(\mathrm{N}=73)$ dos respondentes e notou-se uma mobilidade negativa para 4,2\% $(\mathrm{N}=10)$. 
Tabela 6: Distribuição conjunta de renda percebida, antes e depois a graduação. s.m. = salário mínimo.

\begin{tabular}{|c|c|c|c|c|c|c|}
\hline $\begin{array}{c}\text { Faixa de renda } \\
\text { mensal }\end{array}$ & \multicolumn{4}{|c|}{ Situação após a graduação } & \multicolumn{2}{c|}{$\begin{array}{c}\text { Antes da } \\
\text { graduação }\end{array}$} \\
\hline Antes da graduação & Desempregado & $\begin{array}{c}\text { Até 2 } \\
\text { s.m }\end{array}$ & $\begin{array}{c}\mathbf{3} \text { a } \mathbf{4} \\
\text { s.m }\end{array}$ & $\begin{array}{c}\mathbf{5} \text { a 7 } \\
\text { s.m }\end{array}$ & $\begin{array}{c}\text { Mais de } \\
\mathbf{8} \text { s.m }\end{array}$ & Total \\
\hline Sem renda & 25 & 33 & 55 & 18 & 8 & 139 \\
\hline Até 2 s.m. & 6 & 25 & 21 & 5 & 2 & 59 \\
\hline 3 a 4 s.m. & 3 & 1 & 11 & 9 & 2 & 26 \\
\hline $\mathbf{5}$ a 7 s.m. & 0 & 0 & 0 & 8 & 3 & 11 \\
\hline Mais de 8 s.m. & 0 & 0 & 0 & 0 & 4 & 4 \\
\hline $\begin{array}{c}\text { Total depois da } \\
\text { graduação }\end{array}$ & 34 & 59 & 87 & 40 & 19 & 239 \\
\hline
\end{tabular}

Constatou-se que os rendimentos dos egressos foram relativamente baixos. A maioria passou a receber de 3 a 4 salários mínimos, sendo uma média de 3,3 salários mínimos. Antes da graduação, o mais frequente era "não trabalhar", sendo que somente $24,7 \%$ da amostra apresentaram rendimentos acima de 5 salários mínimos e 7,9\% possuíam rendimentos superiores a 8 salários mínimos. No outro extremo da distribuição, a proporção de graduados desempregados foi maior (14,2\%), conforme apresentado na Figura 3.

Figura 3: Distribuição de renda dos egressos antes e depois da graduação.

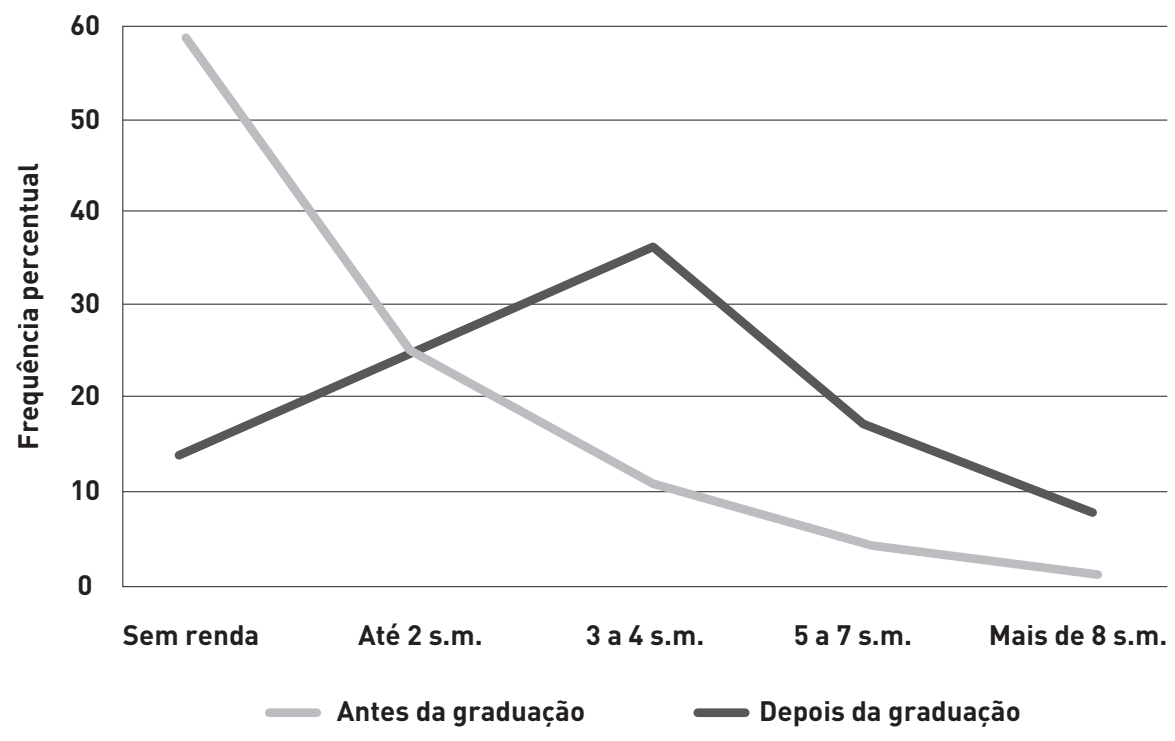


Conforme demonstrado na Tabela 7, os melhores parâmetros de renda foram observados entre os egressos da UFRJ e os salários mais baixos foram os da UERJ e da USU. Na UERJ, 26,5\% dos egressos não apresentaram renda e somente $2,9 \%$ declararam renda acima de 8 salários mínimos, enquanto que entre os egressos da UFRJ, 12,1\% apresentaram renda superior a 8 salários mínimos. Acima da mediana geral de renda, estão as medianas dos egressos da UFRJ e UENF.

Foi observada mobilidade positiva de classe de renda para 65,2\% dos respondentes. No entanto, somente $51,4 \%$ atribuíram a elevação de renda à graduação. Por outro lado, 89,6\% dos respondentes atribuíram à graduação como contribuição principal para melhorar seu desempenho profissional e um percentual maior, de 95,8\% dos respondentes atribuiu à graduação a maior contribuição para elevar sua posição social, considerando-se respeito, prestígio e status.

Tabela 7: Distribuição por instituição das frequências relativas de renda.

\begin{tabular}{|c|c|c|c|c|c|c|}
\hline & EaD & UENF & UERJ & UFRJ & USU & Geral \\
\hline Sem renda & 11,0 & 10,9 & 26,5 & 9,1 & 18,2 & 14,2 \\
\hline Até 2 salários mínimos & 32,9 & 23,9 & 11,8 & 15,2 & 27,3 & 24,7 \\
\hline 3 a 4 salários mínimos & 30,5 & 43,5 & 41,2 & 36,4 & 36,4 & 36,4 \\
\hline 5 a 7 salários mínimos & 17,1 & 13,0 & 17,6 & 27,3 & 11,4 & 16,7 \\
\hline Mais de 8 salários mínimos & 8,5 & 8,7 & 2,9 & 12,1 & 6,8 & 7,9 \\
\hline
\end{tabular}

\section{PROCURA POR PADRÕES PARA AS DISTINTAS CLASSES DE RENDA}

Em relação ao gênero, os homens passaram a receber mais, como mostrado estatisticamente ( $\mathrm{p}$-valor=0.001). A mediana da renda da mulher foi de 3,2 salários mínimos e a mediana da renda dos homens foi de 3,7 salários mínimos. Convém salientar que dentre os que ganhavam mais de 8 salários mínimos, 63,2\% eram homens e 36,8\% mulheres. Dentre os sem renda, $82,3 \%$ eram mulheres e apenas $17,6 \%$ homens. A proporção de homens que ganhava mais de 8 salários mínimos foi de 18,8\%, ou seja, foi mais de 4 vezes maior que a das mulheres $(4,0 \%)$. 


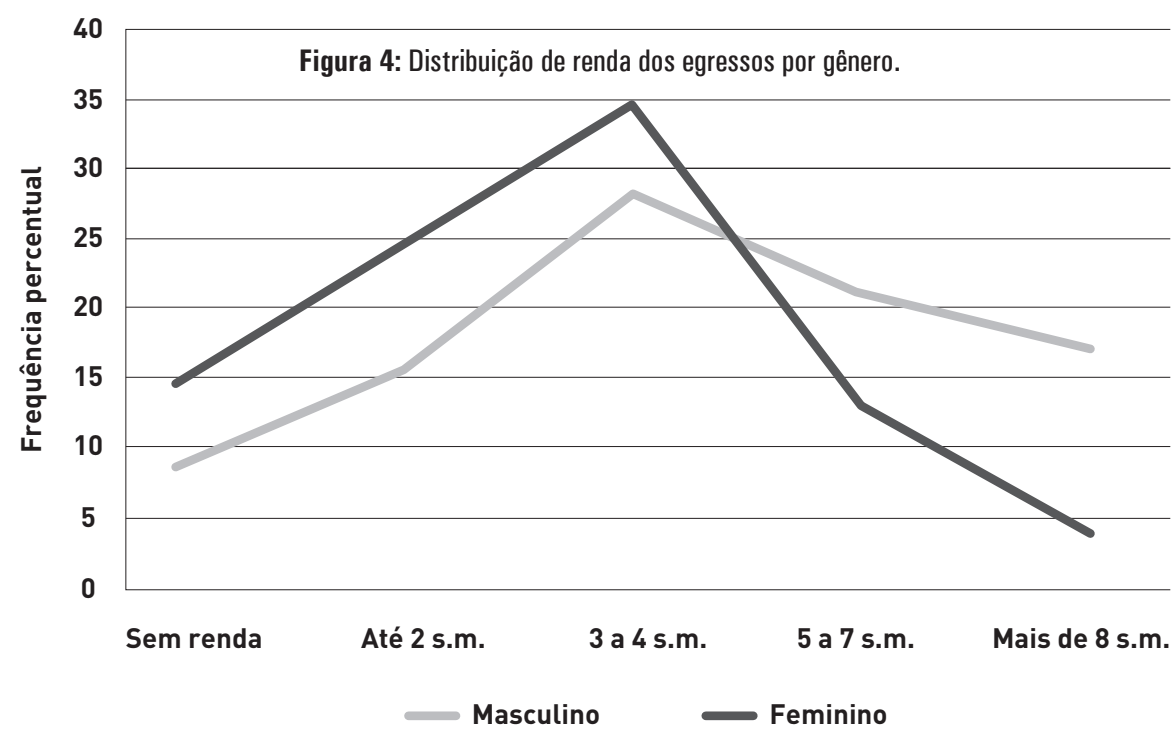

Quando tentou-se relacionar o nível salarial em relação à cor do egresso, verificamos que os brancos tinham renda mais elevada (3,5 salários mínimos). A segunda maior foi dos pretos (3,3 salários mínimos) e os menores rendimentos ocorreram nos indígenas (1,0 salário mínimo) e amarelos (0,8 salário mínimo). Além disso, estes últimos apresentaram o maior número de desempregados.

Quando comparada a renda por modalidade do curso, observou-se não existir diferença significativa nas proporções de profissionais formados a distância e aqueles da modalidade presencial nas distintas faixas de renda ( $p$-valor=0.229). Conclui-se que o rendimento do profissional de Ciências Biológicas independe da modalidade do curso feito, a mediana da renda dos que fizeram o curso a distância foi de 3,2 salários mínimos e daqueles que fizeram o curso presencial foi de 3,3 salários mínimos.

Quando comparada a renda do presencial público com o presencial privado, também não foram observadas diferenças significativas ( $\mathrm{p}$-valor $=0.588$ do teste Qui-quadrado). A mediana de renda do grupo presencial público foi de 3,4 salários mínimos enquanto do presencial privado foi de 3,1 salários mínimos. Os maiores salários foram encontrados no grupo de egressos das universidades públicas.

Em relação ao fato de o egresso ter uma segunda graduação, foi bem distinta a distribuição de renda. A renda mediana dos que possuíam curso superior foi de 6,0 salários mínimos, comparados com aqueles que não tinham (3,3 salários mínimos). Contudo, o teste Qui-quadrado ficou inconclusivo devido ao baixo tamanho amostral do grupo de egressos que possuía outra graduação $(n=15)$.

Comparando a distribuição de frequências de renda de quem estava trabalhando na área e de quem estava fora da área, não foram verificadas diferenças 
significativas entre os grupos ( $\mathrm{p}$-valor $=0.356$, do teste Qui-quadrado). A mediana de renda de quem trabalhava fora da área foi a mesma de quem trabalhava na área (3,5 salários mínimos).

A renda mediana de quem tinha apenas uma única atividade profissional foi de 3,3 salários mínimos. Para os egressos que exerciam duas atividades profissionais, a renda mediana foi de 3,7 salários mínimos e para os que exerciam três atividades, a renda mediana foi de 3,8 salários mínimos. Notou-se, assim, que o efeito de ter mais atividades não está relacionado ao aumento proporcional de renda, em termos medianos. Observou-se que a renda dos profissionais de Ciências Biológicas não se relacionou com o número de atividades profissionais que o egresso exerce.

\section{APRIMORAMENTO PROFISSIONAL}

Os resultados de distribuição de renda tomando-se como parâmetro os que fizeram pós-graduação mostraram que os egressos que possuíam doutorado não apresentaram os maiores salários. Pelo contrário, eles não tiveram nenhuma representação na classe "acima de 8 salários mínimos" e apresentaram mediana pouco superior a dos demais grupos, conforme pode ser observado na Tabela 8.

Tabela 8: Distribuição de renda de acordo com o nível de pós-graduação realizada.

\begin{tabular}{|c|c|c|c|c|c|c|c|}
\hline Pós-graduação & $\begin{array}{c}\text { Sem } \\
\text { renda }\end{array}$ & $\begin{array}{c}\text { Até } \mathbf{2} \\
\text { s.m }\end{array}$ & $\begin{array}{c}\mathbf{3} \text { a } \mathbf{4} \\
\text { s.m }\end{array}$ & $\begin{array}{c}\mathbf{5} \text { a } \mathbf{7} \\
\mathbf{5 . m}\end{array}$ & $\begin{array}{c}\text { Mais de } \\
\mathbf{8} \text { s.m }\end{array}$ & Total & Mediana \\
\hline Doutorado & 5 & 1 & 10 & 7 & 0 & 23 & 3,5 \\
\hline$(\%)$ & 21,7 & 4,3 & 43,5 & 30,4 & 0,0 & 100 & \\
\hline Mestrado & 13 & 9 & 25 & 9 & 2 & 59 & 3,3 \\
\hline$(\%)$ & 22,0 & 15,3 & 44,1 & 15,3 & 3,4 & 100 & \\
\hline $\begin{array}{c}\text { Pós-graduação } \\
(\text { Lato sensu) }\end{array}$ & 2 & 11 & 12 & 5 & 6 & 37 & 3,5 \\
\hline$(\%)$ & 5,4 & 32,4 & 32,4 & 13,5 & 16,2 & 100 & \\
\hline Não respondeu & 14 & 37 & 39 & 19 & 11 & 120 & 3,2 \\
\hline$(\%)$ & 11,7 & 30,8 & 32,5 & 15,8 & 9,2 & 100 & \\
\hline Total & 34 & 59 & 87 & 40 & 19 & 239 & 3,3 \\
\hline$(\%)$ & 14,2 & 24,7 & 36,4 & 16,7 & 7,9 & 100 & \\
\hline
\end{tabular}

\section{CONCLUSÕES}

Os resultados encontrados nesta pesquisa permitiram traçar o perfil, a situação profissional e de renda de alguns grupos de egressos graduados em 
Ciências Biológicas no estado do Rio de Janeiro. Verificou-se que, tipicamente, o profissional formado era do sexo feminino, de cor branca e idade média de conclusão do curso de 23 anos, para os egressos do ensino presencial, e 33 anos, do ensino a distância. A média de idade ao se formar dos egressos nas instituições de ensino presencial pública (UENF-UERJ-UFRJ) pode ser considerada igual, entre 22 e 23 anos, porém, foi significativamente distinta dos graduados pela EaD (CEDERJ) e pela rede privada (USU). Em geral, os alunos da EaD se formaram com idade superior e os alunos da USU se formaram mais novos.

A licenciatura foi a habilitação típica, sendo comumente a primeira e única formação superior ao nível de graduação. Fora desse perfil, destacaram-se os egressos da USU que têm as duas habilitações (bacharelado e licenciatura). Foi comum também que apenas os egressos do ensino presencial tenham realizado iniciação científica na graduação. A maioria dos ex-alunos da modalidade presencial prosseguiu os estudos em nível de pós-graduação na área, mais frequentemente cursando o Mestrado. Apenas os egressos do CEDERJ não seguiram esse padrão, sendo os que menos fizeram pós-graduação.

Antes de cursarem a graduação, os egressos dos cursos presenciais não trabalhavam, diferente do que acontecia com os alunos do CEDERJ que, em sua maioria, eram servidores públicos. Após a graduação, de modo interessante, quem era oriundo de instituições públicas de ensino passou a ser predominantemente servidor público, enquanto que os da USU foram para a rede privada. Ao prestar concursos, foi alto o índice de aprovação entre os egressos do CEDERJ e das instituições públicas presenciais. Entretanto, entre os egressos da USU foi mais comum a não aprovação em concursos públicos.

A atividade profissional dos egressos modal foi a docência (tanto a principal fonte de renda como a secundária). Além dessa atividade, observou-se pouca diversidade dos que estavam trabalhando na área: somente 6,6\% trabalhavam com auditoria/consultoria especializada, 2,9\% como biólogos, 2,1\% executavam trabalhos técnicos em laboratório e $0,4 \%$ faziam outra atividade na área.

Dentre os que atuavam no magistério, a maioria trabalhava na rede pública estadual, com maior frequência de professores concursados que lecionavam no Ensino Fundamental II e no Ensino Médio.

A classe de renda típica dos egressos do CEDERJ, UENF, UERJ foi a de 3 a 4 salários mínimos. Já para os egressos formados na UFRJ, a moda ocorreu na classe de 3 a 4 salários mínimos e de 5 a 7 salários mínimos, e dos da USU, de 3 a 4 salários mínimos e de até 2 salários mínimos.

Dentre os fatos positivos evidenciados na pesquisa, destacamos a elevação significativa do nível salarial e a redução no número de pessoas sem atividade profissional após a graduação. As taxas de mobilidade positiva de atividade profissional e de renda foram sempre maiores que as taxas de mobilidade nula e de mobilidade negativa. As taxas de mobilidade negativa foram baixas, como esperado, não chegando a 10\% em nenhuma das análises. 
Entretanto, convém ressaltar que para uma população de pessoas com curso superior, pós-graduados e com mais de uma atividade remunerada, em um estado considerado como importante centro econômico e de atividades do país, consideramos baixos os parâmetros de renda para os egressos de Ciências Biológicas. A mediana de renda geral foi de 3,3 salários mínimos e flutuou em torno de 3,5 salários mínimos para a maioria dos subgrupos investigados, sendo que muitos poucos subgrupos superaram 4 salários mínimos.

$\mathrm{Na}$ distribuição de renda por gênero, repetiu-se também, nessa população, o que se observa em outras pesquisas, que mostram que as mulheres, embora sejam maioria no mercado profissional de Ciências Biológicas, apresentaram menores rendas que os homens. Deve-se ressaltar que, apesar de serem maioria, de terem conquistado espaço, elas ainda estão na base da pirâmide de renda. O homem também apresentou maior frequência nas altas classes de renda. Além disso, entre as mulheres, a proporção de profissionais sem atividade profissional foi bem maior.

A investigação gerou indícios de que o fato do egresso ter outro curso superior estaria relacionado a rendimentos muito maiores do que os rendimentos dos que não possuíam outro curso superior, mas o teste de significância para essa inferência foi inconclusivo devido ao pequeno tamanho amostral. Também há indícios apontando que o nível de pós-graduação não garante altos níveis de renda para esses profissionais, mas, neste caso, também as análises ficaram inconclusivas devido às particulares exigências do teste Qui-quadrado. Propõe-se investigar essas hipóteses em trabalhos futuros.

O teste de significância se mostrou conclusivo em outras investigações, apontando que não houve diferença entre a distribuição de renda de egressos da modalidade presencial e da modalidade a distância. Também não houve diferenças significativas entre a distribuição de rendas dos egressos do presencial público e do presencial privado. A distribuição de renda também sugere ser independente do tipo de habilitação (bacharelado, licenciatura ou ambos) e também do fato de trabalharem na área ou não.

Esperamos que os resultados obtidos nesta investigação possam ter revelado características e padrões importantes acerca da população que foi alvo do estudo, ou confirmar hipóteses desses egressos já conhecidas na prática. Sugere-se que estudos semelhantes sejam realizados em outros contextos universitários e repetidos posteriormente para que as características, pontos positivos e negativos, possam ser mapeados, possíveis padrões ou fatores globais e locais sejam identificados e a dinâmica temporal dos parâmetros seja observada. Avaliar o egresso é uma forma de a instituição avaliar o produto do seu trabalho. Trabalhar para melhorar o sucesso e a identidade profissional de seus egressos deve ser uma meta de toda instituição de ensino realmente comprometida com a formação e a transformação da sociedade em cada uma das áreas que atua. 


\section{AGRADECIMENTOS}

Os autores agradecem a contribuição dos alunos egressos da Fundação CECIERJ/CEDERJ (Centro de Educação a Distância do Estado do Rio de Janeiro), da Universidade Federal do Rio de Janeiro (UFRJ), da Universidade do Estado do Rio de Janeiro (UERJ), Universidade Estadual do Norte Fluminense Darcy Ribeiro (UENF) e da Universidade Santa Úrsula (USU) que participaram desta pesquisa, indispensável para a realização deste trabalho. Agradecemos, ainda, à Fundação Carlos Chagas Filho de Amparo à Pesquisa do Estado do Rio de Janeiro (FAPERJ).

\section{REFERÊNCIAS}

CABRERA, A. F.; WEERTZ, D. J.; ZULICK, B. J. Making an impact with alumni surveys. New Directions for Institutional Research, v. 126, p. 5-17, 2005.

DELANEY, A. M. Voices of experience: renewing higher education with alumni studies. Tertiary Education and Management, v. 6, n. 2, p. 137-155, 2000.

FREITAS, A. M. As Competências na atuação do profissional egresso da Licenciatura em Ciências Biológicas da UNESC: uma análise dos anos de 2002 a 2005. 2007. 62f. Dissertação (Mestrado em Educação)-Universidade do Extremo Sul Catarinense-UNESC, Criciúma, 2007.

INEP. Resumo técnico: censo da educação superior de 2009. Brasília, DF: Instituto Nacional de Estudos e Pesquisas Educacionais Anísio Teixeira (INEP). 34p. 2010.

ROSSI, C. A. V.; SLONGO, L. A. Pesquisa de satisfação de clientes: o estado-da-arte e proposição de um método brasileiro. Revista de Administração Contemporânea, Curitiba, v.2, n.1, p. 101-125, 1998.

VASCONCELOS, S. D.; LIMA, K. E. C. O Professor de Biologia em Formação: reflexão com base no perfil socioeconômico e perspectivas de licenciandos de uma universidade pública. Ciência \& Educação, Bauru, v.16, n.2, p. 323-240, 2010. 